\title{
Comparative bionomics of four populations of Meccus longipennis (Hemiptera: Reduviidae: Triatominae) under laboratory conditions
}

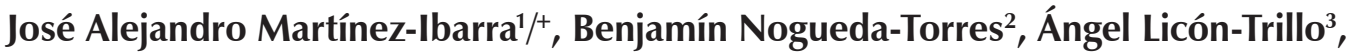 \\ María Elena Villagrán-Herrera ${ }^{4}$, José Antonio de Diego-Cabrera ${ }^{5}$, \\ Oziel Dante Montañez-Valdez ${ }^{6}$, Gonzalo Rocha-Chávez ${ }^{6}$
}

\begin{abstract}
'Área de Entomología Médica ${ }^{6}$ Departamento de Desarrollo Regional, Centro Universitario del Sur,
Universidad de Guadalajara, Ciudad Guzmán, Jalisco, México ²Comisión de Operación y Fomento de Actividades Académicas, Escuela Nacional de Ciencias Biológicas, Instituto Politécnico Nacional, Colonia Casco de Santo Tomás, México DF, México

${ }^{3}$ Facultad de Medicina, Universidad Autónoma de Chihuahua, Chihuahua, Chihuahua, México ${ }^{4}$ Departamento de Investigación Biomédica, Facultad de Medicina, Universidad Autónoma de Querétaro, Santiago de Querétaro, Querétaro, México

${ }^{5}$ Departamento de Medicina Preventiva y Salud Pública, Facultad de Medicina, Universidad Autónoma de Madrid, Madrid, España
\end{abstract}

The values of biological parameters related to the life cycles of four populations of Meccus longipennis (Reduviidae: Triatominae) were evaluated. Cohorts of each of the four studied populations from different geographical areas of Mexico were maintained under similar laboratory conditions and then compared. The population from El Saucito de Araujo was different from the other three studied populations, which could help explain the secondary importance of $\mathrm{M}$. longipennis in the state of Chihuahua. This paper also supports the proposition that biological traits are important criteria for determining relationships between populations.

Key words: Meccus longipennis - populations - biological variation - life statistics - laboratory conditions

In Mexico, Meccus longipennis (Usinger), 1939, together with the other six species of the Phyllosoma complex, is considered to be responsible for $74 \%$ of vectorial transmissions of Trypanosoma cruzi to humans (Ibarra-Cerdeña et al. 2009). The triatomine species $M$. longipennis is considered an important vector for $T$. cruzi and is distributed in eight states of western, central and northern Mexico (Licón-Trillo et al. 2010, SalazarSchettino et al. 2010). Different studies (Martínez-Ibarra et al. 2003a, 2006) that used morphometrical analysis of head phenotypes and isoenzymes of populations of $M$. longipennis from different areas of Mexico have shown that populations of $M$. longipennis from proximal geographical areas are very similar. However, two studies using morphometrics of antennal phenotypes, internal transcribed spacer- 2 markers and five polymorphic microsatellite loci reported similarity for non-close populations of M. longipennis (Martínez-Martínez et al. 2010, Breniere et al. 2012). Additionally, different biological traits have been studied and it has been concluded that different biological traits are important criteria for determining the relationships between species or between populations of the same species (Grech et al. 2010). Thus, we conducted a study to investigate the feeding behaviour and life cycles of four populations of M. longipennis from western, central and northern Mexico.

+ Corresponding author: aibarra@cusur.udg.mx

Received 22 May 2012

Accepted 3 August 2012
Four laboratory colonies of $M$. longipennis, which were established in 2009 from at least 30 specimens collected from localities with different environmental characteristics in four different Mexican states (Figure) were used. The localities were Jala, in the state of Nayarit, El Saucito de Araujo, in the state of Chihuahua, Pénjamo, in the state of Guanajuato, and Sayula, in the state of Jalisco. Jala $\left(21^{\circ} 05^{\prime} \mathrm{N} 104^{\circ} 24^{\prime} \mathrm{W}\right)$ is $1.080 \mathrm{~m}$ above sea level (a.s.1.), has a subhumid climate and is characterised by the presence of pine (Pinus spp), holm oak and oak forest (Quercus spp), otate (Guadua angustifolia Kunth) and fir [Abies religiosa (Kunth) Schltdl. \& Cham]. El Saucito de Araujo $\left(26^{\circ} 06^{\prime} \mathrm{N} 106^{\circ} 56^{\prime} \mathrm{W}\right)$ is $2.320 \mathrm{~m}$ a.s.l., has a semi-humid climate and is primarily characterised by the presence of pine (Pinus spp), holm oak and oak forest (Quercus spp), tepehuaje [Lysiloma acapulcensis (Kunth) Benth] and pochote [Ceiba pentandra (L.) Gaertn]. Pénjamo $\left(20^{\circ} 25^{\prime} \mathrm{N} 101^{\circ} 42^{\prime} \mathrm{W}\right)$ is $1.700 \mathrm{~m}$ a.s.l., has a temperate climate and is primarily characterised by the presence of mesquite (Prosopis spp L.). Sayula (19 $52^{\prime} \mathrm{N} 103^{\circ} 34^{\prime} \mathrm{W}$ ) is $1.350 \mathrm{~m}$ a.s.l., has a semidry climate and is characterised by the presence of huizache [Acacia farnesiana (L.)], pitayo [Stenocereus queretaroensis (FAC Weber) Buxb] and some sown fields of tomatoes (Solanum lycopersicum L.) (SEGOB 2010).

The specimens were identified according to the taxonomic key of Lent and Wygodzinsky (1979), taking into account the revalidation of the genus Meccus (Carcavallo et al. 2000). The studied colonies were maintained under conditions similar to those in a previously published study on the biology of $M$. longipennis (Martínez-Ibarra et al. 2003b) and kept at $27^{\circ} \mathrm{C} \pm 1{ }^{\circ} \mathrm{C}$ and $75 \% \pm 5 \%$ relative humidity (RH). The colonies were fed on immobilised and anaesthetised New Zealand rabbits on a fortnightly basis. The rabbits were anaesthetised following the 


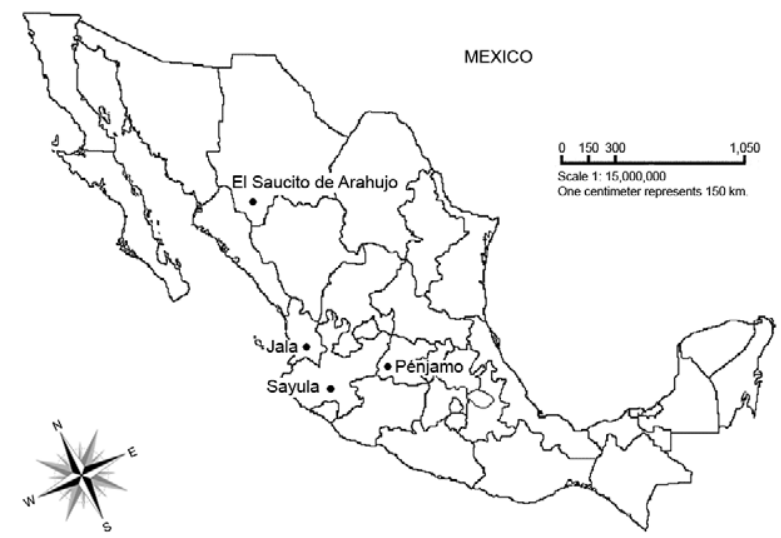

Localities where the founders of the studied populations where initially collected.

Norma Oficial Mexicana regulations by administering $0.25 \mathrm{~mL} / \mathrm{kg}$ of ketamine through intramuscular inoculation (SAGARPA 1999). The eggs from each colony were grouped by date of oviposition to initiate cohorts with a population of 200 eggs each. After eclosion, the groups of each species of first-instar nymphs were separated individually into plastic containers $(5.5 \mathrm{~cm}$ diameter $\mathrm{x}$ $10.5 \mathrm{~cm}$ height) with a central vertical support of absorbent cardboard. Three days after eclosion, each cohort of nymphs was individually fed (as previously described) during a 1-h period; the subsequent blood meals were given fortnightly. The nymphs were observed at the end of feeding to record blood ingestion. The insects were maintained as previously described: in a dark incubator with a 12:12 h light/dark photoperiod and checked daily for ecdysis or death. At the end of the cycle, the female/ male ratio and percentages of females and males in each studied cohort were recorded. Among the insects that completed development into adults, 10 adult pairs from each cohort were placed in individual containers $(5.5 \mathrm{~cm}$ diameter x $10.5 \mathrm{~cm}$ height) and maintained as previously described to determine the oviposition patterns. Eggs were collected and counted daily for 90 days and placed in individual containers until hatching. Nonparametric Kruskal-Wallis analysis was performed to compare the numbers of eggs laid per female, development cycle periods and number of blood meals between moults in the three studied cohorts because the Bartlett's tests were $p$ $<0$ for all the comparisons. Pairwise comparisons were performed for intergroup comparisons using Dunn's method. A chi-square test was used to compare frequencies. Differences were considered significant at $\mathrm{p}<$ 0.05 . The average incubation periods for the four studied cohorts varied from 19.2 $\pm 1.3-19.4 \pm 1.6$ days, with no significant differences. The average incubation periods were similar to that for Triatoma recurva (Stål), 1868, a related species. The average egg-to-adult development time for the four studied cohorts was approximately sixand-a-half months; however, the development time was significantly longer for the cohort from El Saucito de Araujo, whereas no significant differences between the other three studied cohorts were recorded (Table I). The average egg-to-adult development time, which was approximately 200 days, was similar to that for Triatoma protracta (Uhler), 1894 and M. longipennis in a previous study (Martínez-Ibarra et al. 2003b, 2012). This result reflects the favourability of the maintenance conditions for the development of $M$. longipennis. It could also indicate a potential risk of an increase in the abundance of any of those populations under favourable conditions, similar to Rhodnius neglectus Lent, 1954 and Rhodnius robustus Larrouse, 1927 (Barreto-Santana et al. 2011). This finding could result in an increase in the risk for transmission of $T$. cruzi to hosts in the distribution areas for M. longipennis species. The average number of blood meals between moults was approximately 10 in the four studied populations. The population from El Saucito de Araujo had a significantly different average number of blood meals between moults compared with the population from Pénjamo (Table I). Approximately $70-80 \%$ of most instars in each of the studied cohorts from Jala, Pénjamo and Sayula required an average of one-and-ahalf meals prior to moulting to the next instar, whereas the cohort from El Saucito de Araujo needed two-anda-half meals prior to moulting. The necessity for more blood meals indicates a need for a higher incidence of vector-host interactions, which could indicate a disadvantage in places where hosts are not easily obtained, such as in the main habitats (caves) of M. longipennis in its distribution area in the state of Chihuahua (Licón-

\section{TABLE I}

Egg-to-adult development cycle (days), mean number of blood meals to reach adult stage and mortality of four populations of Meccus longipennis fed every seven days on rabbits

\begin{tabular}{lcccccccc}
\hline & \multicolumn{3}{c}{ Jala } & \multicolumn{2}{c}{ El Saucito de Araujo } & \multicolumn{2}{c}{ Pénjamo } & \multicolumn{2}{c}{ Sayula } \\
\cline { 2 - 9 } & $\mathrm{n}$ & Mean $\pm \mathrm{SD}$ & $\mathrm{n}$ & Mean $\pm \mathrm{SD}$ & $\mathrm{n}$ & Mean $\pm \mathrm{SD}$ & $\mathrm{n}$ & Mean $\pm \mathrm{SD}$ \\
\hline Development cycle & 121 & $194.1 \pm 20.9^{a}$ & 86 & $211.8 \pm 31.9^{b}$ & 101 & $196.9 \pm 22.3^{a}$ & 123 & $193.9 \pm 17.4^{a}$ \\
Blood meals & - & $91.1 \pm 1.1^{a, b}$ & - & $10.7 \pm 1.2^{b}$ & - & $8.9 \pm 1.6^{\mathrm{a}}$ & - & $9.4 \pm 1.2^{a, b}$ \\
Mortality (\%) & - & $18.3^{a}$ & - & $18.9^{a}$ & - & $24^{a}$ & - & $20.8^{a}$ \\
\hline
\end{tabular}

similar letters within a line indicate no significant $(\mathrm{p}>0.05)$ differences. SD: standard deviation. 


\section{TABLE II}

Percentages of each sex at the end of the cycles, egg eclosion rate and mean number of eggs laid per female per day in four populations of Meccus longipennis

\begin{tabular}{lcccc}
\hline & Females & Males & & Egg eclosion rate \\
\cline { 2 - 3 } Population & $\mathrm{n}(\%)$ & $\mathrm{n}(\%)$ & $\begin{array}{c}\text { Fecundity per } \\
\text { female per day }\end{array}$ \\
\hline Jala & $59\left(48.8^{a}\right)$ & $62\left(51.2^{a}\right)$ & $76.5^{a}$ & $1.2 \pm 0.7^{a}$ \\
El Saucito de Araujo & $60\left(49.2^{a}\right)$ & $62\left(50.8^{a}\right)$ & $54.8^{b}$ & $1.4 \pm 0.6^{a}$ \\
Pénjamo & $63\left(52.1^{a}\right)$ & $58\left(47.9^{a}\right)$ & $64.6^{b}$ & $1.2 \pm 0.8^{a}$ \\
Sayula & $64\left(52.1^{a}\right)$ & $59\left(49.9^{a}\right)$ & $79.2^{a}$ & $1.9 \pm 0.5^{a}$ \\
\hline
\end{tabular}

similar letters within a line indicate no significant $(p>0.05)$ differences.

Trillo et al. 2010). The mortality rates were not significantly different (Table I) between the four studied cohorts and were lower than those for T. recurva, a related species (Martínez-Ibarra et al. 2012). The mortality rates were also slightly lower than those for M. longipennis in a previous study (Martínez-Ibarra et al. 2003b). As reported for T. recurva, T. protracta and Triatoma rubida (Uhler), 1894, mortality in the youngest nymphs of $M$. longipennis appeared to be caused by the inability of the insects to feed because dead triatomines were generally found without significant intestinal content. In contrast, the mortality of older nymphs appeared to occur during moulting. At the end of the cycles, the female/male ratios were 1:1 in the four studied populations. No significant differences were recorded when percentages of obtained females were compared between studied populations. A similar phenomenon was observed when the percentages of males were compared (Table II). The abundance of females led us to conclude that the four studied populations have the same potential to increase their abundance under favourable conditions, resulting in an increase in the risk of transmission of $T$. cruzi to hosts in their distributions areas. Similar results regarding female:male ratios have been recorded for three Mexican-American species (T. recurva, T. protracta and T. rubida) (Martínez-Ibarra et al. 2012). The amount of eggs laid per female per day after 90 days was not significantly different among the four studied populations (Table II). The similarity of the four studied cohorts with regard to this parameter reflects the high grade of adaptation of $M$. longipennis females, which come from original populations from very different environmental areas to the controlled conditions of this study. The hatching rate was significantly lower in the cohort from El Saucito de Araujo compared with the other three cohorts (Table II). The egg eclosion rate was greater than $75 \%$ for the populations from Jala and Sayula, similar to M. longipennis in a previous study (Martínez-Ibarra et al. 2003b). However, in the cohort from El Saucito de Araujo, only slightly more than half of the eggs laid hatched. This phenomenon could also help explain the low abundance of $M$. longipennis in its distribution area in the state of Chihuahua (Licón-Trillo et al. 2010).
Most of the parameters studied support the conclusion that the population from El Saucito de Araujo is different from the other three species examined here, which could help explain the secondary importance of this species in the state of Chihuahua (Licón-Trillo et al. 2010). In contrast, the other three populations were more similar to each other, which could explain the importance of M. longipennis in the states of Guanajuato, Jalisco and Nayarit (Salazar-Schettino et al. 2010). The concordance of our results with other morphological and genetic studies (Martínez-Martínez et al. 2010, Breniere et al. 2012) supports the proposition that biological traits are important criteria for determining relationships between populations (Grech et al. 2010).

\section{REFERENCES}

Barreto-Santana D, Starling J, Gurgel-Gonçalves R, Cuba-Cuba CA 2011. Biologia comparativa e comportamiento alimentar de Rhodnius neglectus e Rhodnius robustus (Triatominae) sob condições de laboratorio. Rev Soc Bras Med Trop 44: 490-495.

Breniere SF, Waleckx E, Magallón-Gastélum E, Bosseno MF, Hardy X, Ndo C, Lozano-Kasten F, Barnabé C, Kengne P 2012. Population genetic structure of Meccus longipennis (Hemiptera, Reduviidae, Triatominae), vector of Chagas disease in West Mexico. Infect Genet Evol 12: 254-262.

Carcavallo R, Jurberg J, Lent H, Noireau F, Galvão C 2000. Phylogeny of the Triatominae (Hemiptera: Reduviidae): proposal for taxonomic arrangements. Entomol Vect 7 (Suppl. 1): 1-99.

Grech MG, Ludueña-Almeida F, Almirón WR 2010. Bionomics of Aedes aegypti subpopulations (Diptera: Culicidae) from Argentina. $J$ Vector Ecol 35: 277-285.

Ibarra-Cerdeña CN, Sánchez-Cordero V, Townsend-Peterson A, Ramsey JM 2009. Ecology of North American Triatominae. Acta Trop 110: 178-186.

Lent H, Wygodzinsky P 1979. Revision of the triatominae (Hemiptera: Reduviidae) and their significance as vectors of Chagas disease. Bull Am Mus Nat Hist 163: 123-520.

Licón-Trillo A, Balsimelli-De La Peña K, Acosta-Legarda M, LealSolís I, Nogueda-Torres B, Martínez-Ibarra JA 2010. Infección natural por Trypanosoma cruzi en triatominos del Centro y Norte de México. Bol Malariol Salud Ambient 50: 311-313.

Martínez-Ibarra JA, Bárcenas-Ortega NM, Nogueda-Torres B, Ramírez-Vallejo P, Rodríguez MH 2003a. Genetic variability 
among populations of Triatoma longipennis, vector of Chagas disease in Western Mexico. Southwest Entomol 28: 145-151.

Martínez-Ibarra JA, Grant-Guillén Y, Martínez-Grant DM 2003b. Feeding, defecation and development times of Meccus longipennis Usinger, 1939 (Hemiptera: Reduviidae: Triatominae) under laboratory conditions. Mem Inst Oswaldo Cruz 98: 899-903.

Martínez-Ibarra JA, Bárcenas-Ortega NM, Romero-Nápoles J, Nogueda-Torres B, Rodríguez MH 2006. Diferencias métricas entre poblaciones de Meccus longipennis (Hemiptera: Reduviidae) en el occidente de México. Folia Entomol Mex 45(2): 83-90.

Martínez-Ibarra JA, Paredes-González E, Licón-Trillo Á, MontañezValdez OD, Rocha-Chávez G, Nogueda-Torres B 2012. The biology of three Mexican-American species of Triatominae (Hemiptera: Reduviidae): Triatoma recurva, Triatoma protracta and Triatoma rubida. Mem Inst Oswaldo Cruz 107: 659-663.

Martínez-Martínez I, Martínez-Hernández F, Martínez-Ibarra JA, Espinoza-Gutiérrez BJ 2010. Estudio de poblaciones de Meccus longipennis empleando análisis de fenotipo antenal y microsatélites polimórficos. Entomol Mex 9: 916-920.

SAGARPA - Secretaría de Agricultura, Ganadería, Desarrollo Rural, Pesca y Alimentación 1999. Norma Oficial Mexicana NOM-062-ZOO-1999. Especificaciones técnicas para la producción, cuidado y uso de los animales de laboratorio. [cited 13 February 2012]. Available from: fmvz.unam.mx/fmvz/principal/ archivos/062ZOO.PDF.

Salazar-Schettino PM, Rojas-Wastavino GE, Cabrera-Bravo M, Bucio-Torres M, Martínez-Ibarra JA, Monroy-Escobar MC, RodasRetana A, Guevara-Gómez Y, Vences-Blanco MO, Ruiz-Hernández AL, Torres-Gutiérrez E 2010. A revision of thirteen species of Triatominae (Hemiptera: Reduviidae) vectors of Chagas disease in Mexico. $J$ Selva Andina Res Soc 1: 57-80.

SEGOB - Secretaría de Gobernación 2010. Enciclopedia de los municipios de México. [cited 6 February 2012]. Available from: inafed. gob.mx/wb2/ELOCAL/ELOC_Enciclopedia. 